\title{
Research on Fuzzy Adaptive PID Control Algorithm Based on Siemens PLCSIM
}

\author{
Chengwu Lin ${ }^{\mathrm{a}}$, Miao Liu ${ }^{\mathrm{b}}$, Jianguang Zhu ${ }^{\mathrm{c}}$ \\ Department of Information Science and Engineering \\ Shenyang University of Technology \\ Shenyang, China 110870

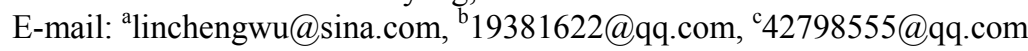

\begin{abstract}
Studied the realization method of the fuzzy adaptive PID algorithm based on SIEMENS PLC. Fuzzy control algorithm bases on the mode of calculation offline and query online, and with the help of indirectly addressing the memories of PLC. It's proved that the fuzzy algorithm has good control effect by testing the arithmetic with the PLCSIM simulation software.
\end{abstract}

\section{Keywords- fuzzy contorl;PID; PLC;PLCSIM}

\section{INTRODUCTION}

Fuzzy control is the use of fuzzy logic to sum up the human experience as a qualitative description of the conditional statement, and then be quantified use the fuzzy theory to make the controller accept the human's experience and mimic the operation of thinking, which formed a fuzzy controller [1]. In industrial control, programmable logic controller has the extremely wide range of applications. If combined the fuzzy control technology and PLC, the application of PLC to realize the fuzzy controller will make the fuzzy control play a greater role in industrial control. This paper designs fuzzy adaptive PID algorithm achieved in the S7-300 and implements by PLCSIM simulation capabilities, then intuitive display via WinCC Flexible monitoring renderings. This can make engineering staff visually see the difference and advantages with the traditional PID, and be familiar with the concept of fuzzy control.

\section{FUZZY ADAPTIVE PID ALGORITHM}

Core of the fuzzy PID control designing is a summary of the engineering staffs' technical knowledge and practical experience, the establishment of appropriate fuzzy rule table, getting against scaling factor, integral coefficient and differential coefficient of three parameters tuning fuzzy control table [2].

The theory of fuzzy adaptive PID controller is shown in Fig.1. Fuzzy PID controller makes its rate of change of the deviation ec and the deviation e as input, $\triangle \mathrm{k}_{\mathrm{p}}, \triangle \mathrm{k}_{\mathrm{I}}$ and $\triangle \mathrm{k}_{\mathrm{D}}$ as output, and turns PID parameters online automatically [3].

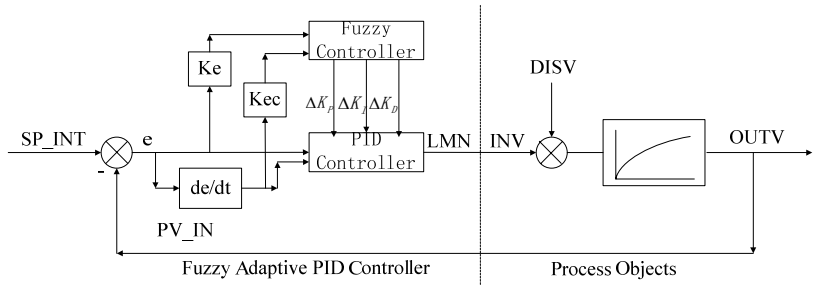

Figure 1. Fuzzy adaptive PID simulation diagram

\section{A. Interface Fuzzy}

First we defined on $\mathrm{E}$ in the domain of e linguistic variables, defined on the EC in the domain of ec linguistic variables. Set the deviation e basic domain $\{\mathrm{el}, \mathrm{eh}\}=\{-$ $30,30\}$, error change rate ec basic domain $\{$ ecl, ech $\}=\{-$ $12,12\}, \triangle \mathrm{k}_{\mathrm{P}}$ basic domain $\{-0.3,0.3\}, \triangle \mathrm{k}_{\mathrm{I}}$ basic domain $\{-$ $0.3,0.3\}, \triangle \mathrm{k}_{\mathrm{D}}$ basic domain $\{-0.06,0.06\}$.

The design of the fuzzy controller has two inputs and three outputs. In order to make fuzzy set better cover the theory domain set, and reduce the amount of computation in the premise, determine the deviation e and the deviation change rate ec the universe is: $\{-3,-2,-1,0,1,2,3\}$; fuzzy PID controller variation $\triangle \mathrm{k}_{\mathrm{P}}, \triangle \mathrm{k}_{\mathrm{I}}$ the domain of $\{-0.3,-0.2$, $0.1,0,0.1,0.2,0.3\}$; of the domain is $\{-0.06,-0.04$, $0.02,0,0.02,0.04,0.06\}$. Fuzzy set is $\{\mathrm{NB}, \mathrm{NM}, \mathrm{NS}, \mathrm{ZO}, \mathrm{PS}$, $\mathrm{PM}, \mathrm{PB}$, the subset elements represent \{negative, negative middle, the negative small $\triangle \mathrm{k}_{\mathrm{D}}$, zero, positive small, positive middle, positive $\}$.

According to the above settings, quantization factor and scale factor are calculated as follows:

$$
\begin{gathered}
\mathrm{Ke}=2 \mathrm{n} / \mathrm{eh}-\mathrm{el}=6 / 60=0.1 \\
\mathrm{Kec}=2 \mathrm{n} / \mathrm{ech}-\mathrm{ecl}=6 / 24=0.25 \\
\Delta \mathrm{Kkp}=\Delta \mathrm{Kki}=\Delta \mathrm{Kkd}=\Delta \mathrm{K} / \mathrm{n}=6 / 6=1
\end{gathered}
$$

\section{B. Fuzzy Rules and Illation}

The rules of fuzzy PID control are based on the control of people with long-term understanding of the theory lessons and learned technically artificial. Fuzzy self-tuning PID parameters rule:

1) When $|\mathrm{e}|$ is large, should take larger $\triangle \mathrm{k}_{\mathrm{P}}$ and smaller $\triangle \mathrm{k}_{\mathrm{D}}$ in order to speed up the response of the system, and take a smaller $\triangle \mathrm{k}_{\mathrm{I}}$ in order to avoid a greater overshoot restrict the integral action [4]; 
2) When $\mid$ e $\mid$ is medium, in order to make the system has a smaller overshoot, $\triangle \mathrm{k}_{\mathrm{P}}$ should be made smaller. At this point, $\triangle \mathrm{k}_{\mathrm{D}}$ has greater impact on the system, should get smaller, $\triangle \mathrm{k}_{\mathrm{I}}$ values should be appropriate;

3) When $\mid$ e $\mid$ is small, to make the system has good stability, should take a larger $\triangle \mathrm{k}_{\mathrm{P}}$ and $\triangle \mathrm{k}_{\mathrm{I}}, \triangle \mathrm{k}_{\mathrm{D}}$ should be appropriate in order to avoid oscillation occurs near the equilibrium point.

According to the above rules may draw the following 49 fuzzy relations:

1) If (e is NB) and (ec is NB), then ( $\triangle \mathrm{k}_{\mathrm{p}}$ is PB) $\left(\triangle \mathrm{k}_{\mathrm{I}}\right.$ is NB) $\left(\triangle \mathrm{k}_{\mathrm{D}}\right.$ is PS);

2) If (e is NB) and (ec is NM), then $\left(\triangle \mathrm{k}_{\mathrm{p}}\right.$ is $\left.N B\right)\left(\triangle \mathrm{k}_{\mathrm{I}}\right.$ is $\mathrm{PB})\left(\triangle \mathrm{k}_{\mathrm{D}}\right.$ is $\left.\mathrm{PM}\right)$;

3) If (e is NB) and (ec is NS), then ( $\triangle \mathrm{k}_{\mathrm{p}}$ is PM) $\left(\triangle \mathrm{k}_{\mathrm{I}}\right.$ is $\mathrm{NM})\left(\triangle \mathrm{k}_{\mathrm{D}}\right.$ is $\left.\mathrm{NB}\right)$;

49) If (e is PB) and (ec is PB), then $\left(\triangle k_{p}\right.$ is NB) $\left(\triangle k_{I}\right.$ is PB) $\left(\triangle \mathrm{k}_{\mathrm{D}}\right.$ is $\left.\mathrm{PB}\right)$;

Mamdani fuzzy reasoning, due to its form of rules in line with people's habits of thought and language, and thus can be easily expressed human knowledge. In this simulation, we those Mamdani inference method.

\section{Ambiguity Resolution}

Defuzzification methods currently used in three ways: as the maximum membership degree method, median method and the weighted average method [5]. To obtain accurate output variables, we use the weighted average method. This method is a fuzzy control system is widely used as a decision method.

According to the fuzzy control rules and the application of fuzzy reasoning method to calculate the fuzzy adaptive PID controller fuzzy control decision table as shown in TABLE I .

TABLE I. $\triangle K_{P}$ FUZZY CONTROL DECISION TABLE

\begin{tabular}{cccccccc}
\hline $\mathbf{e c}$ & $\mathbf{- 3}$ & $\mathbf{- 2}$ & $\mathbf{- 1}$ & $\mathbf{0}$ & $\mathbf{1}$ & $\mathbf{2}$ & $\mathbf{3}$ \\
\hline-3 & 0.268 & 0.268 & 0.2 & 0.2 & 0.1 & 0.128 & 0.128 \\
-2 & 0.268 & 0.268 & 0.2 & 0.109 & 0.1 & -0.008 & -0.0914 \\
-1 & 0.2 & 0.2 & 0.2 & 0.1 & -3 & -0.1 & -0.1 \\
0 & 0.2 & 0.2 & 0.1 & -3 & -0.1 & -0.2 & -0.2 \\
1 & 0.1 & 0.1 & -3 & -0.1 & 0.1 & -0.2 & -0.2 \\
2 & 0.091 & 0.008 & -0.109 & -0.2 & -0.2 & -0.2 & -0.268 \\
3 & -3 & -3 & -0.2 & -0.2 & -0.2 & -0.268 & -0.268 \\
\hline
\end{tabular}
tables.

\section{FUZZY ADAPTIVE PID ALGORITHM}

\section{A. Program Structure and Flow Chart}

Fuzzy Control program structure is shown in Fig.2. OB1 is the main program for the control system started and stopped and subroutine calls. Organization block OB35 cycle terminal, OB100 used to achieve third-order simulation program. As fuzzy PID controller, FB1completes the fuzzy adaptive PID control functions. It consists of FC1 $\sim$ FC4 4 sub-routines. Where FC1 calculates e (deviation) and ec (deviation change rate); FC2 is fuzzy processing completed and accurate volume e and ec to E and EC; FC3 completes fuzzy control table query capabilities; FC4 completes antiblur function.

Data block DB10 is used for storing setting values, measured values, the output error, the error change rate and quantization values. Data block DB11, DB12 and DB13 are used to store fuzzy control query table $\triangle \mathrm{k}_{\mathrm{p}}, \triangle \mathrm{k}_{\mathrm{I}}$ and $\triangle \mathrm{k}_{\mathrm{D}}$.

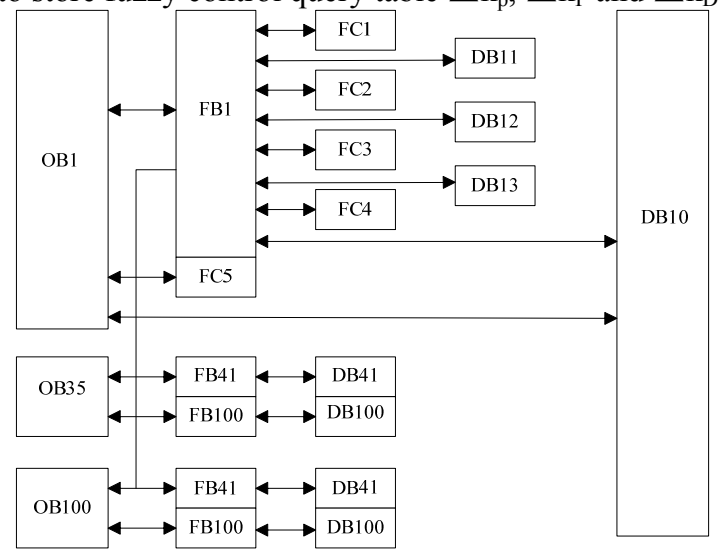

Figure 2. PLC program structure diagram

FB1 fuzzy controller to complete the preparation, save in STEP7 standard library, which has great flexibility and versatility, as easy as in STEP7 PID controller (FB41). As long as configure the input and output side correctly to fuzzy control for different controlled variables. Fuzzy Adaptive PID controller design flow chart is shown in Fig.3.

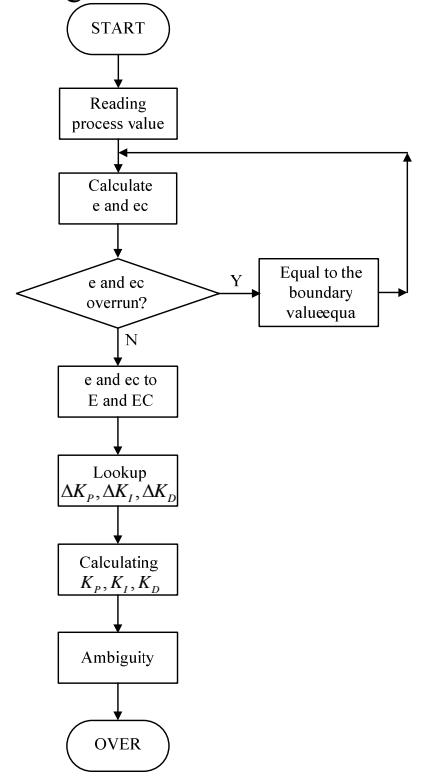

Figure 3. Fuzzy adaptive PID control program flow chart 


\section{B. Data Block Design}

In order to make fuzzy adaptive controller is similar FB41PID controllers, fuzzy control parameters need to be stored in the data block, using DB10, DB11, DB12, DB13 four data blocks, followed by the required storage quantify fuzzy control factor quantization value and fuzzy control table and other data. Because the PLC's internal memory address is 32 bits, so the rate of change of the error and error $\mathrm{E}$ and $\mathrm{EC}$, and quantization factor value set to 32-bit integer data.

Fuzzy control for quantitative data stored in DB10, the initial value of its numeric types shown in TABLE II .

TABLE II. DB10 DATA PARAMETER VALUES

\begin{tabular}{|c|c|c|c|}
\hline Address & Name & Initial value & Description \\
\hline \multicolumn{4}{|l|}{0.0} \\
\hline+0.0 & $\mathrm{Ke}$ & $1.000000 \mathrm{e}-001$ & Error quantization factor \\
\hline+4.0 & Kec & $2.500000 \mathrm{e}-001$ & Error change rate factor \\
\hline+8.0 & $\mathrm{~K} 3$ & $1.000000 \mathrm{e}+000$ & Quantization factor Kp \\
\hline+12.0 & K4 & $1.000000 \mathrm{e}+000$ & Quantization factor $\mathrm{Ki}$ \\
\hline+16.0 & K5 & $1.000000 \mathrm{e}+000$ & Quantization factor Kd \\
\hline+20.0 & $\mathrm{Kp}$ & $5.000000 \mathrm{e}+001$ & The initial value of Kp \\
\hline+24.0 & $\mathrm{Ki}$ & $2.000000 \mathrm{e}+001$ & The initial value of $\mathrm{Ki}$ \\
\hline+28.0 & $\mathrm{Kd}$ & $1.000000 \mathrm{e}+000$ & The initial value of $\mathrm{Kd}$ \\
\hline+32.0 & Kp1 & $0.000000 \mathrm{e}+000$ & Kp output values \\
\hline+36.0 & Kil & $0.000000 \mathrm{e}+000$ & $\mathrm{Ki}$ output values \\
\hline+40.0 & $\mathrm{Kd} 1$ & $0.000000 \mathrm{e}+000$ & Kdoutput values \\
\hline$=44.0$ & & & \\
\hline
\end{tabular}

\section{Program Design}

1) Program design fuzzy rule-table query

This paper gives only part of the program (deviation e is 3 , the offset is stored as 0 inquiry procedures). MW22 stored quantized values of e and MW32 stored quantized values of ec. First determine the fuzzy table row, using MW22 quantization range of values of $e$ determines the corresponding output compare operation in the fuzzy table row, and then activating the corresponding row of columns, that the corresponding line of column elements are compared to determine the assignment operator dimensional fuzzy control query values in DB11 and assign the exact location of the storage area in place memory word MW10. At the end of each line of inquiry procedures, the implementation of a conditional jump action, that if the bit memory area memory bit M50.0 power (complete fuzzy query table work), the program jumps to CASE1 which control the amount of output assignment procedure. This greatly reduces the PLC jump action query working time. The program is shown in Fig.4.

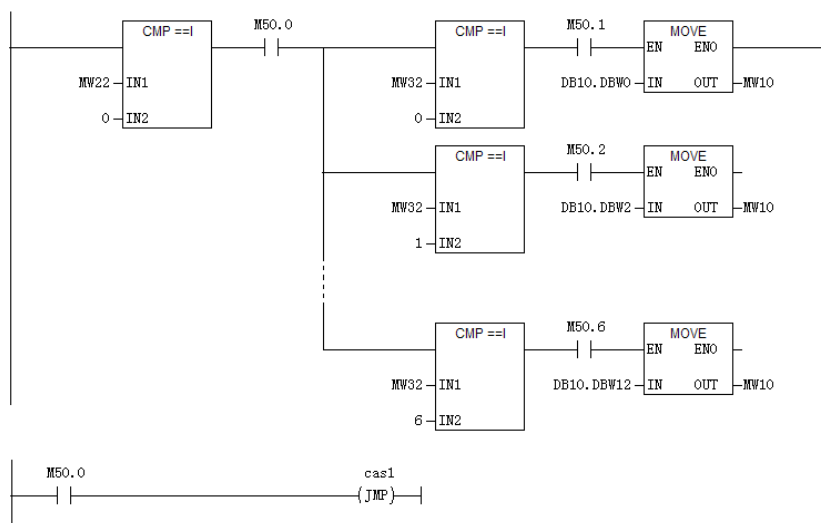

Figure 4. Fuzzy rule table query ladder program

2) Defuzzification output program design

After getting the query results, you need to MW10 data with the PID module calculated TAIN, TI and TD are summed, and then output to the actuator. Program DB41.DBW20 $~ 28$ PID parameters were stored TAIN, TI and TD, MW10 12 tables were stored queries get blurred, the correction value, and TAIN, TI and TD summed output, which completed the fuzzy adaptive PID control as shown in Fig.5.

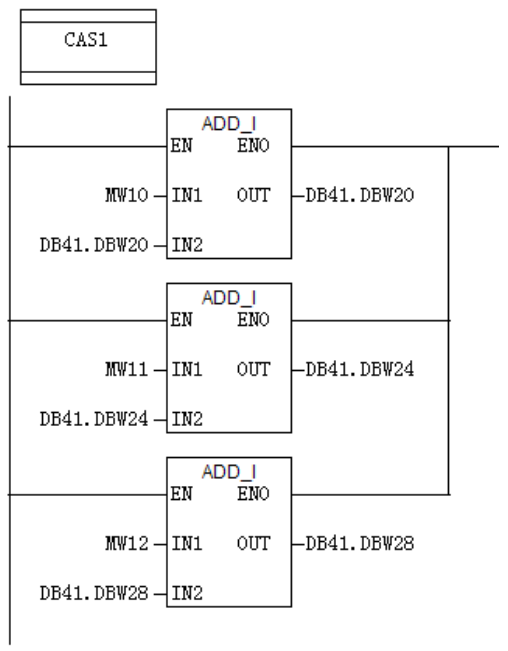

Figure 5. Output ladder program

\section{SimUlation TESTING AND ANALYSIS}

Open fuzzy PID control project, download the finished program into the PLCSIM, click the Run button and open the WinCC Flexible monitor screen to monitor fuzzy PID control curves.

Fuzzy PID controller sets point from $20 \%$ to $70 \%$ for a period of $20 \mathrm{~s}$ for a step change in the trend view corresponding given green signal square wave, the controlled object output variable trace as black curve.

Here is the initial PID set point, proportional coefficient 1.8 , integration time of $4 \mathrm{~s}$, derivative time is $0.8 \mathrm{~s}$. Analog control object as $3 /(6 s+1)(5 s+1)(1 s+1)$. 
Conventional PID parameter adjustment process and the effect of adjustment and fuzzy adaptive PID control effect shown in Fig. 6 and Fig.7.

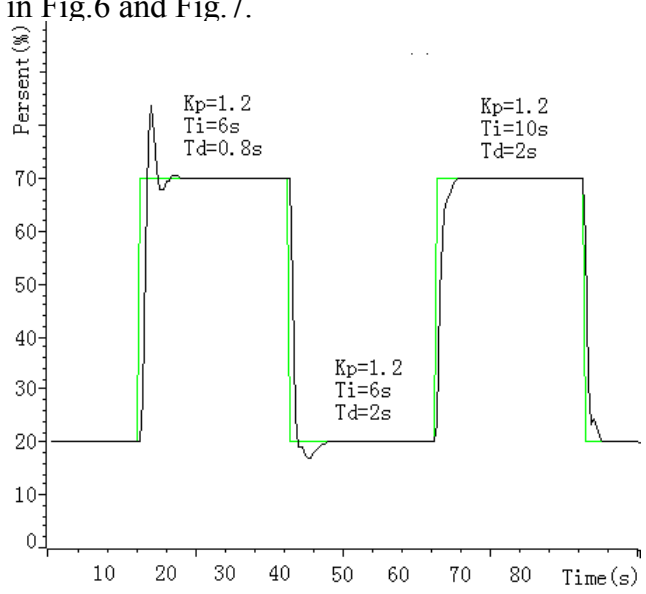

Figure 6. Conventional PID control renderings

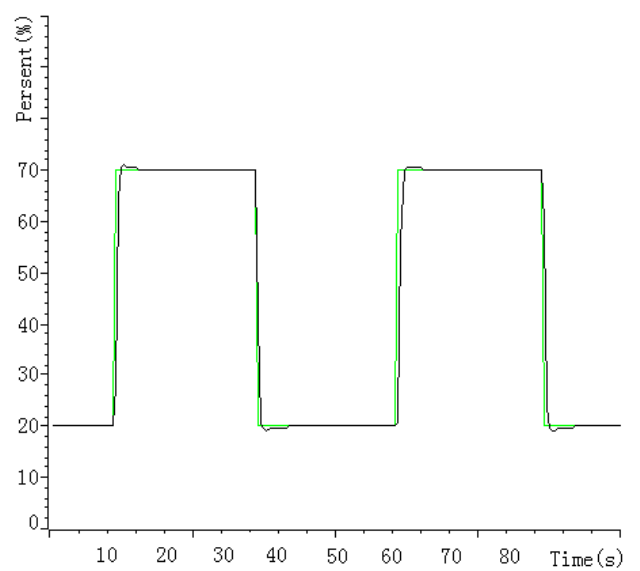

Figure 7. Fuzzy Adaptive PID Control renderings
As shown in Fig.6, adjust the PID parameters: to ensure that the gain and integration time constantly, increasing the differential time, you can see that the system settling time reduced overshoot quantity is small. It shows that differential time can affect the system overshoot and speed up the system response speed; on this basis, strengthen integration action, you can see that the system overshoot is almost zero, but greatly increases the rise time. Fuzzy Adaptive PID's rise time, settling time and overshoot, and other static and dynamic performance are superior to conventional PID control obviously in Fig.7.

\section{USING THE TEMPLATE}

Experiments show that this procedure concise design and realization of fuzzy control offline calculation and online inquiry. In the fuzzy lookup table is not the case, it will be greatly improving the efficiency of the PLC program, and conducive to enhancing real-time control. Focus is to provide a process object do not depend on accurate mathematical model of fuzzy control method for a specific project application.

\section{REFERENCES}

[1] Gengxing Luo, "Fuzzy self-tuning PID parameter controller in the furnace gas flow control application," Southern Metal, pp. 25-28, May 2007.

[2] Lei Wang, Weimin Wang, Fuzzy Control Theory and Applications, National Defense Industry Press. Bejing, 1997, pp.19-29.

[3] Jinhuan Zhang, "PID control system and the fuzzy adaptive PID control system Research and Compare," Wuhan University of Technology, pp. 286-289. October 2005.

[4] Changchu Liao, "The most popular explanation PID parameter tuning method and parameters," Electric Age, pp. 90-94, January 2012.

[5] R. Nicole, "A General Practical Design Method for Fuzzy PID Control from Conventional PID Control,” Fuzzy Systems, pp.969-97. February 2005 